\title{
Ascorbate and thiol antioxidants abolish sensitivity of yeast Saccharomyces cerevisiae to disulfiram
}

\author{
Magdalena Kwolek-Mirek • \\ Renata Zadrag-Tecza • Grzegorz Bartosz
}

Received: 5 May 2011 / Accepted: 11 August 2011 /Published online: 25 August 2011

(C) The Author(s) 2011. This article is published with open access at Springerlink.com

\begin{abstract}
Sensitivity of baker's yeast to disulfiram (DSF) and hypersensitivity of a mutant devoid of $\mathrm{Cu}$, $\mathrm{Zn}$-superoxide dismutase to this compound is reported, demonstrating that yeast may be a simple convenient eukaryotic model to study the mechanism of DSF toxicity. DSF was found to induce oxidative stress in yeast cells demonstrated by increased superoxide production and decrease of cellular glutathione content. Anoxic atmosphere and hydrophilic antioxidants (ascorbate, glutathione, dithiothreitol, cysteine, and $\mathrm{N}$-acetylcysteine) ameliorated DSF toxicity to yeast indicating that oxidative stress plays a critical role in the cellular action of DSF.
\end{abstract}

Keywords Antioxidant - Disulfiram - Oxidative stress $\cdot$ Superoxide dismutase $\cdot$ Saccharomyces cerevisiae Yeast

Abbreviations
ALDH acetaldehyde dehydrogenase
ASC ascorbate

M. Kwolek-Mirek $(\bowtie) \cdot$ R. Zadrag-Tecza $\cdot$ G. Bartosz Department of Biochemistry and Cell Biology, University of Rzeszow, ul. Zelwerowicza 4, 35-601 Rzeszow, Poland e-mail: mkwolek@univ.rzeszow.pl

G. Bartosz

Department of Molecular Biophysics, University of Lodz, ul. Pomorska 141/143,

90-237 Lodz, Poland

$\begin{array}{ll}\text { CYS } & \text { cysteine } \\ \text { DDC } & N, N \text {-diethyldithiocarbamate } \\ \text { DHET } & \text { dihydroethidine } \\ \text { DSF } & \text { disulfiram } \\ \text { DTT } & \text { dithiothreitol } \\ \text { EDTA } & \text { ethylenediaminetetraacetic acid } \\ \text { GSH } & \text { reduced glutathione } \\ \text { GSSG } & \text { oxidized glutathione } \\ \text { MeDDC } & S \text {-methyl- } N, N \text {-diethyldithiocarbamate } \\ \text { MeDTC } & S \text {-methyl- } N, N \text {-diethylthiocarbamate } \\ \text { NAC } & N \text {-acetylcysteine }\end{array}$

\section{Introduction}

Disulfiram (DSF, Antabuse) is a drug used to support the treatment of chronic alcoholism by producing an extremely aversive reaction when taken in the presence of alcohol, and is thus considered a deterrent. DSF prevents conversion of acetaldehyde to the harmless acetic acid by blocking acetaldehyde dehydrogenase (ALDH, EC 1.2.1.10).

In the presence of reduced glutathione (GSH), disulfiram is rapidly reduced in vivo to $N, N$-diethyldithiocarbamate (DDC), which is methylated to form $S$ methyl- $N, N$-diethyldithiocarbamate (MeDDC). MeDDC is oxidized primarily to the intermediate metabolite MeDDC sulfine, which is ultimately converted to $S$ methyl- $N, N$-diethylthiocarbamate (MeDTC) sulfoxide, the proposed active metabolite of disulfiram in vivo, 
and a small amount of MeDDC sulfoxide (Pike et al. 2001).

Mechanism of DSF action within a cell is complex and multi-level. DSF and its metabolite-DDC inhibit superoxide dismutase (SOD) in vitro and in vivo by copper chelation (Heikkila et al. 1976; Marikovsky et al. 2003; Kelner and Alexander 1986). Cells incubated with DSF show transient elevation of intracellular superoxide level, and progressive decrease of intracellular $\mathrm{H}_{2} \mathrm{O}_{2}$ level (Cen et al. 2002). Both DSF and DDC may also induce oxidative stress by shifting thiol redox balance. It was reported that DSF does not deplete total glutathione but significantly decreases the reduced glutathione/oxidized glutathione (GSH/GSSG) ratio, by induction of glutathione oxidation (Cen et al. 2002; Burkitt et al. 1998; Namazi 2008). According to Grosicka-Maciag et al., DSF increases catalase and glutathione reductase activities, decreases non-Sedependent glutathione peroxidase (GPx) activity, but does not change Se-dependent GPx in V79 fibroblasts. In contrast to other data, these authors did not reveal changes in SOD-1 and SOD-2 activities (GrosickaMaciag et al. 2010). Several studies have suggested that DSF can induce apoptosis, DNA fragmentation, changes in mitochondrial membrane potential (Cen et al. 2002; Burkitt et al. 1998), and increase of protein carbonyl content (Grosicka-Maciag et al. 2010). Furthermore, DSF inhibits ATP hydrolysis and binds to substrate sites of several $\mathrm{ABC}$ transporters associated with multidrug resistance, blocking their activity (Sauna et al. 2004; Sauna et al. 2005). DSF metabolites like DDC can elevate copper level, leading to oxidative stress, protein damage, lipid peroxidation, and apoptosis in some cell types (Chen et al. 2001; Tonkin et al. 2004; Viquez et al. 2007), whereas MeDDC sulfoxide and MeDDC sulfine can inhibit the verapamil-stimulated ATPase activity of P-glycoprotein (Loo et al. 2004).

DSF, apart from treatment of alcoholism, has been examined as a potential drug effective in protection against Giardia lamblia (Nash \& Rice 1998), Trichomonas vaginalis (Bouma et al. 1998), and leishmaniasis (Namazi 2008); in the therapy of candidiasis (Shukla et al. 2004); as a potential inhibitor of inflammation (Marikovsky et al. 2003); and in alternative therapy of some types of cancers (Cen et al. 2002; Sauna et al. 2005; Navrátilová et al. 2009; Wang et al. 2011). Khan et al. demonstrated antifungal activity of DSF against both yeast and filamentous fungi (Khan et al. 2007).
Previous studies have shown that antioxidants can reduce the cytotoxic effects of DSF treatment; for example, $N$-acetylcysteine (NAC) prevents DSFinduced apoptosis, augments cell viability and the GSH/GSSG ratio in human melanoma cells (Cen et al. 2002), and also prevents the increase in protein carbonyl content induced by disulfiram in V79 cells (Grosicka-Maciag et al. 2010). Dithiothreitol (DTT) completely prevents DSF-induced inhibition of ALDH at $\mathrm{pH} 7.5$ in vitro; however, the inhibition induced by MeDTC is prevented by DTT only at pH 9.0 (Veverka et al. 1997). DTT protects also ATPase activity (Shukla et al. 2004).

In this paper, we show that mutant of yeast Saccharomyces cerevisiae deficient in $\mathrm{Cu}, \mathrm{Zn}$-superoxide dismutase (Sod1p), the enzyme decomposing superoxide anion, is hypersensitive to DSF. We demonstrate that several antioxidants such as ascorbate, cysteine, dithiothreitol, glutathione, and $\mathrm{N}$-acetylcysteine abolish this sensitivity.

\section{Material and methods}

\section{Chemicals}

Disulfiram (tetraethylthiuram disulfide), CAS number 97-77-8, purum, $\geq 97 \%$, was from Aldrich (Sigma-Aldrich, Poznan, Poland). A stock solution of DSF was freshly prepared in absolute ethanol (MERC, Germany) before each experiment. Dihydroethidine (DHET), FUN-1, and MitoTrackerGreen stain were from Molecular Probes (Eugene, Oregon, USA). Monochlorobimane was from Fluka (Sigma-Aldrich, Poznan, Poland). Antioxidants and all other reagents were purchased from SigmaAldrich (Poznan, Poland). Components of culture media were from BD Difco (Becton Dickinson and Company, Spark, USA) except for glucose (POCh, Gliwice, Poland).

Yeast strains and growth conditions

Following yeast strains were used: wild-type SP4 MAT $\alpha$ leu1 arg4 (Bilinski et al. 1978), and $\Delta \operatorname{sod} 1$ mutant, isogenic to SP4, MAT $\alpha$ leul arg4 sod1:: natMX (Koziol et al. 2005). Yeast was grown in standard liquid YPD medium (1\% yeast extract, 1\% yeast bacto-peptone, and $2 \%$ glucose) on a rotary 
shaker at $150 \mathrm{rpm}$ or on solid YPD medium containing $2 \%$ agar, at a temperature of $30^{\circ} \mathrm{C}$.

DSF toxicity assays

Liquid yeast cultures (200 $\mu \mathrm{l}$ of cell suspension containing $1 \times 10^{6}$ cells) with various concentrations of DSF $(0-75 \mu \mathrm{M})$ were cultivated in a Bioscreen $\mathrm{C}$ (Oy Growth Curves Ab Ltd.) incubator with shaking at $30^{\circ} \mathrm{C}$. Their growth was monitored turbidimetrically at $600 \mathrm{~nm}$ for $24 \mathrm{~h}$ (with measurements every $1 \mathrm{~h}$ ).

For spotting tests, yeast exponential phase cultures were diluted to give suspensions of $10^{7}, 10^{6}, 10^{5}$, and $10^{4}$ cells $/ \mathrm{ml}$. Aliquots of $5 \mu \mathrm{l}$ of each suspension were inoculated on solid YPD medium containing DSF ( 0 $100 \mu \mathrm{M})$. Freshly prepared stock solution of DSF was added to sterile media, after cooling to approximately $50^{\circ} \mathrm{C}$. In case of experiments under anaerobic conditions, cells were grown on YPD plates with or without $50 \mu \mathrm{M}$ DSF in a desiccator under the atmosphere of $100 \%$ gaseous oxygen-free nitrogen (Linde Gaz, Cracow, Poland). Colony growth was inspected after $48 \mathrm{~h}$.

In experiments involving antioxidants, cells were grown on liquid or solid YPD medium containing $50 \mu \mathrm{M}$ DSF with various concentration of antioxidants, viz. ascorbate (ASC), cysteine (CYS), dithiothreitol, glutathione (GSH), $N$-acetylcysteine, 2,2,6,6-tetramethylpiperidine-1-oxyl (Tempo), 4-hydroxy2,2,6,6-tetramethylpiperidine-1-oxyl (Tempol), or Trolox. In case of liquid medium, cell growth was inspected after $18 \mathrm{~h}$, and on solid medium after $48 \mathrm{~h}$.

Measurement of reactive oxygen species

Generation of superoxide was assessed with dihydroethidine at the final concentration of $18.9 \mu \mathrm{M}$ (added from a stock solution was prepared in DMSO). Cells from exponential phase culture were centrifuged, washed twice, and suspended in $100 \mathrm{mM}$ phosphate buffer, $\mathrm{pH} 7$, containing $0.1 \%$ glucose and $1 \mathrm{mM}$ ethylenediaminetetraacetic acid (EDTA) and DSF at concentrations of $0,20,50$, and $100 \mu \mathrm{M}$ at a density of $10^{8}$ cells $/ \mathrm{ml}$. After 1,2 , and $3 \mathrm{~h}$ incubation cells were centrifuged, washed twice, and suspended in the same buffer. The kinetics of fluorescence increase, due to oxidation of fluorogenic probe, was measured using a Hitachi F2500 fluorescence spec- trophotometer. Measurement conditions were: $\lambda_{\mathrm{ex}}=$ $518 \mathrm{~nm}$ and $\lambda_{\mathrm{em}}=605 \mathrm{~nm}$; temperature of $30^{\circ} \mathrm{C}$.

Fluorescence microscopy

Cells from exponential phase culture were centrifuged, washed twice, and suspended to a final density of $10^{8}$ cells $/ \mathrm{ml}$ in $100 \mathrm{mM}$ phosphate buffer, $\mathrm{pH} \mathrm{7,}$ containing $0.1 \%$ glucose and $1 \mathrm{mM}$ EDTA, and DSF at concentrations of $0,20,50$, and $100 \mu \mathrm{M}$. After incubation for $3 \mathrm{~h}$ cells were pelleted by centrifugation and washed twice with PBS. The cellular content of glutathione was estimated with monochlorobimane according to a slightly modified method of Staleva et al. (Staleva et al. 2002). Briefly, cells were incubated with $30 \mu \mathrm{M}$ monochlorobimane for $30 \mathrm{~min}$ and then fluorescence of the bimane-glutathione conjugates was observed using excitation wavelength of $480 \mathrm{~nm}$. Mitochondria were stained with MitoTrackerGreen and metabolic activity of yeast cells was assessed with FUN-1 according to the manufacturer's protocols (Molecular Probes). The fluorescence pictures were taken with an OLYMPUS BX-51 microscope equipped with a DP-72 digital camera.

\section{Statistical analysis}

The results represent mean \pm SD from at least three independent experiments. Statistical analysis was performed using the SPSS 17.0 software. The statistical significance of differences between means of treated samples compared to untreated control was estimated using one-way ANOVA and the Dunnet post hoc test. The differences between means of two yeast strains compared were evaluated using the $t$ test for independent samples. Values were considered significant if $P<0.05$.

\section{Results}

A mutant defective in Sod1p is hypersensitive to DSF

Exposure of yeast in both liquid and solid medium to DSF resulted in inhibition of growth in a concentrationdependent manner, $\Delta$ sodl mutant showing much higher sensitivity (Fig. 1a-c). Complete inhibition of growth under the influence of DSF in liquid medium could be observed at a concentration of $75 \mu \mathrm{M}$ for wild 

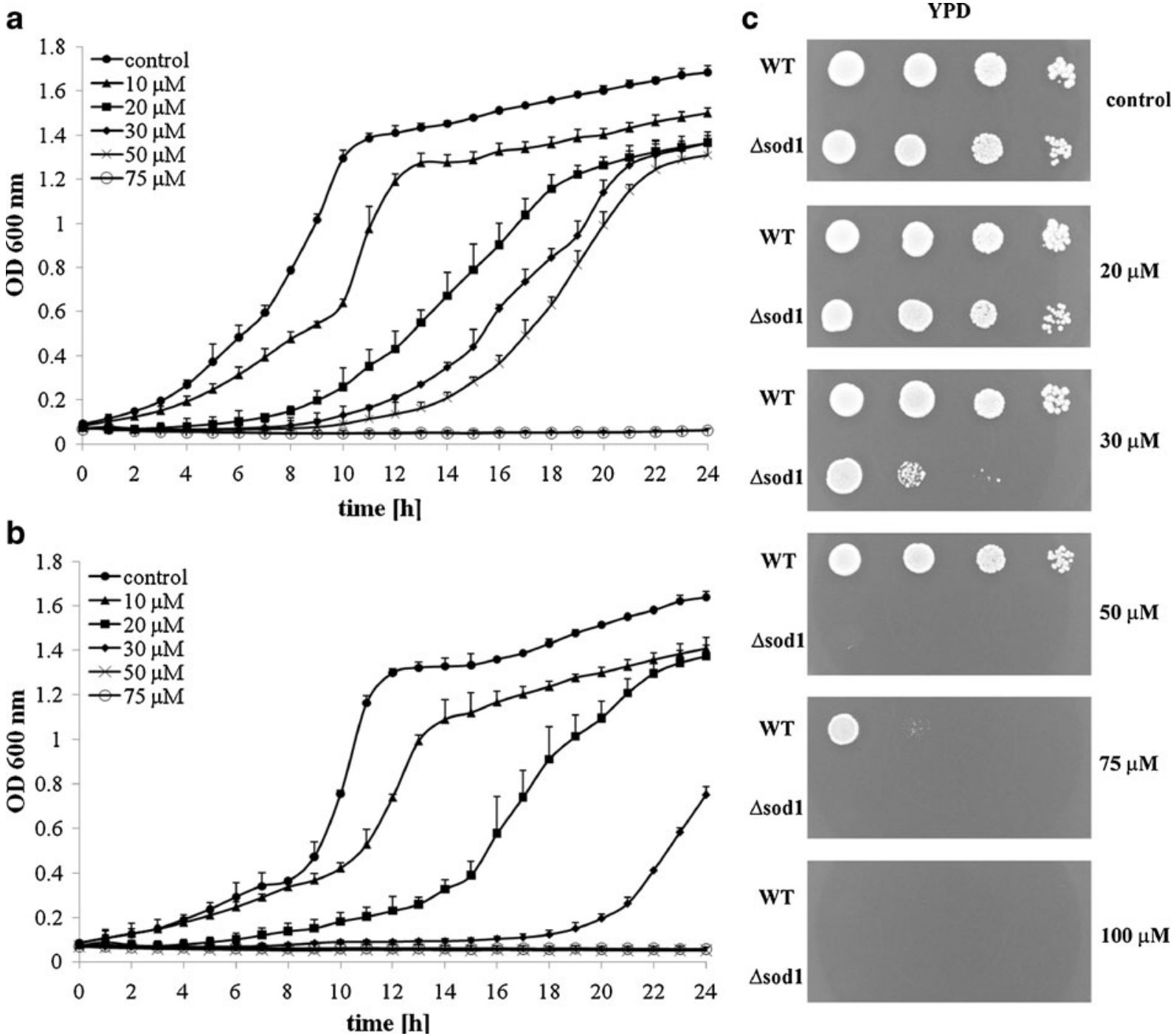

Fig. 1 Effect of DSF $(0-100 \mu \mathrm{M})$ on yeast cell growth on liquid and solid media. Kinetics of growth of WT strain SP4 (a) and $\Delta \operatorname{sod} 1$ mutant (b) was monitored turbidimetrically at $600 \mathrm{~nm}$ every $1 \mathrm{~h}$ for $24 \mathrm{~h}$. Data are presented as mean $\pm \mathrm{SD}$

type (WT) and of $50 \mu \mathrm{M}$ for $\Delta \operatorname{sod} 1$ mutant. However, a $50 \%$ decrease in survival of $\Delta$ sodl mutant was noticed already at $30 \mu \mathrm{M}$ concentration of DSF. Lower concentrations of DSF tested $(10-50 \mu \mathrm{M}$ in the case of WT, and $10-20 \mu \mathrm{M}$ in the case of $\Delta \operatorname{sod} 1)$ did not cause significant inhibition of growth after $24 \mathrm{~h}$ (mortality less than 25\% compared with control), but clearly changed the course of growth curves (Fig. 1a, b). On solid medium, complete inhibition of growth was apparent at the concentration of $100 \mu \mathrm{M}$ DSF in the case of WT and of $50 \mu \mathrm{M}$ DSF in the case of $\Delta$ sodl mutant. Partial inhibition from three independent experiments; $\mathbf{c}$ in spotting tests colony growth was recorded after $48 \mathrm{~h}$. Successive spots contained initially $50,000,5,000,500$, and 50 cells

of growth of WT could be observed from the concentration of $75 \mu \mathrm{M}$, and in the case of $\Delta$ sod1 mutant of $30 \mu \mathrm{M}$ of DSF (Fig. 1c). Both in liquid and on solid medium, there was no effect of introduced amounts of ethanol (DSF solvent) on the growth of yeast cells (data not shown).

DSF induces oxidative stress in yeast cells

Treatment of $\Delta$ sodl mutant cells with 20,50 , and $100 \mu \mathrm{M}$ DSF for 1,2 , and $3 \mathrm{~h}$ induced a significant increase in the rate of ROS generation estimated with 
DHET (Fig. 2). In the case of WT and $\Delta$ sod 1 cells we observed an increased oxidation of DHET after 2 and $3 \mathrm{~h}$ incubation in the buffer. This effect was especially significant in the case of $\Delta \operatorname{sod} 1$ mutant cells. Ethanol (disulfiram solvent) did not cause oxidation of the probe, in the amounts introduced with DSF (data not shown). Yeast cells showed a concentration-dependent decrease in the GSH content after exposure to different concentrations of disulfiram. Changes of intracellular GSH content were greater for $\Delta$ sodl than for WT cells (Fig. 3a). Microscopic visualization showed that exposure of yeast cells to DSF in the concentration range of $20-100 \mu \mathrm{M}$ caused a significant decrease of metabolic activity, increase in cell death frequency, changes of morphology, and mitochondria disintegration, observed especially for $\Delta$ sod1 mutant cells (Fig. $3 \mathrm{~b}, \mathrm{c}$ ).

Antioxidants and anoxia abolish sensitivity of yeast to DSF

The inhibition of growth of $\Delta \operatorname{sod} 1$ mutant cells in the presence of DSF may be overcome by addition of low molecular, hydrophilic antioxidants to growth medium
(Fig. 4a, b). In the case of liquid medium, complete abolition of sensitivity of both yeast strains to $50 \mu \mathrm{M}$ DSF was reached at $5 \mathrm{mM}$ ASC, CYS, GSH, NAC, and at $2.5 \mathrm{mM}$ DTT. No protective effect was observed for $0.5 \mathrm{mM}$ Tempol and $1 \mathrm{mM}$ Trolox, and a slight potentiation of the effect of DSF on WT cells was even noted for $0.5 \mathrm{mM}$ Tempo (Fig. 4a). A similar effect was observed on solid medium: complete abolition of the effect of DSF was achieved for ASC, CYS, GSH, and NAC (1 and $5 \mathrm{mM}$ ), and partial amelioration for DTT $(0.1,1$, and $5 \mathrm{mM})$ while Tempo, Tempol, and Trolox were ineffective (Fig. 4b). Anoxic atmosphere, similarly to antioxidants, led to complete abolishment of growth inhibition of $\Delta \operatorname{sod} 1$ mutant cells in the presence of DSF (Fig. 4c).

\section{Discussion}

Despite of the fact that DSF is mainly known as an inhibitor of aldehyde dehydrogenase, it has also other effects on cells. It has been reported that DSF may induce oxidative stress. This mechanism of DSF action was examined in several mammalian cell lines

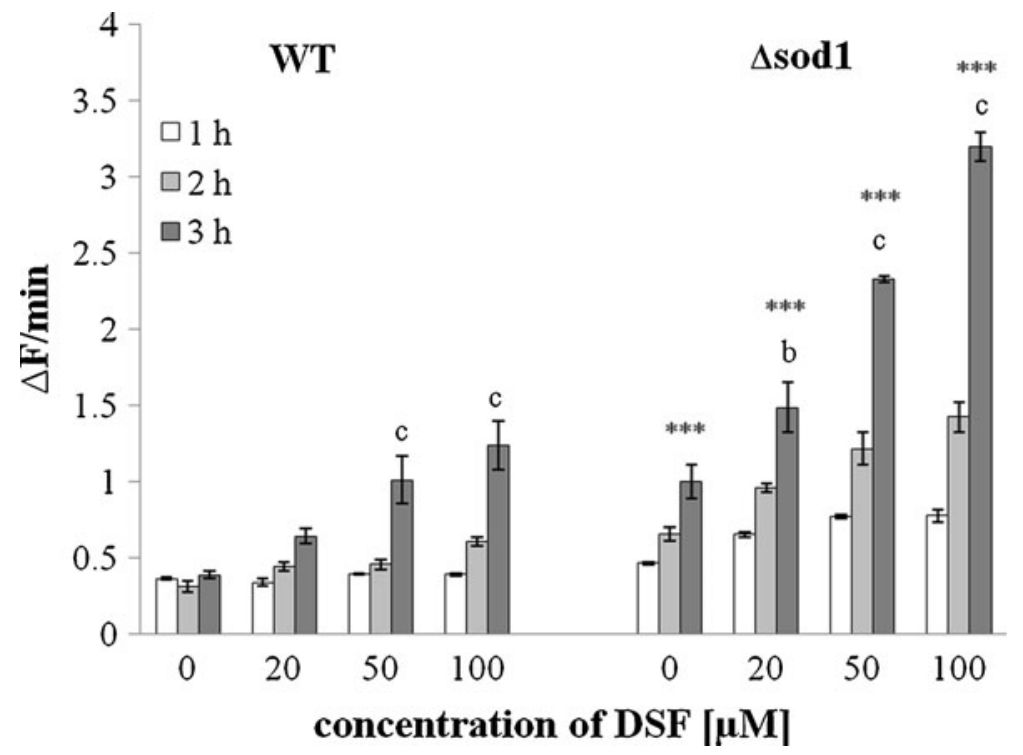

Fig. 2 Superoxide formation in yeast cells after treatment with DSF. Cells were suspended in $0.1 \mathrm{M}$ phosphate buffer, $\mathrm{pH}$ 7.0, containing $0.1 \%$ glucose and $1 \mathrm{mM}$ EDTA and treated with various concentrations of DSF for 1,2 , and $3 \mathrm{~h}$. Superoxide formation was estimated by the rate of fluorescence increase due to DHET oxidation within cells. Data represent mean \pm SD from three independent experiments, asterisks denote statistical significance with respect to wild-type yeast $* * * P<0.001$, estimated by the $t$ test for independent samples. The letters $b$ and $c$ indicate values significantly different from untreated control for the same yeast strain using ANOVA and Dunnet post hoc test at $b P<0.01$ and $c P<0.001$, respectively. Statistical analysis was performed only for samples incubated for $3 \mathrm{~h}$ with or without DSF 

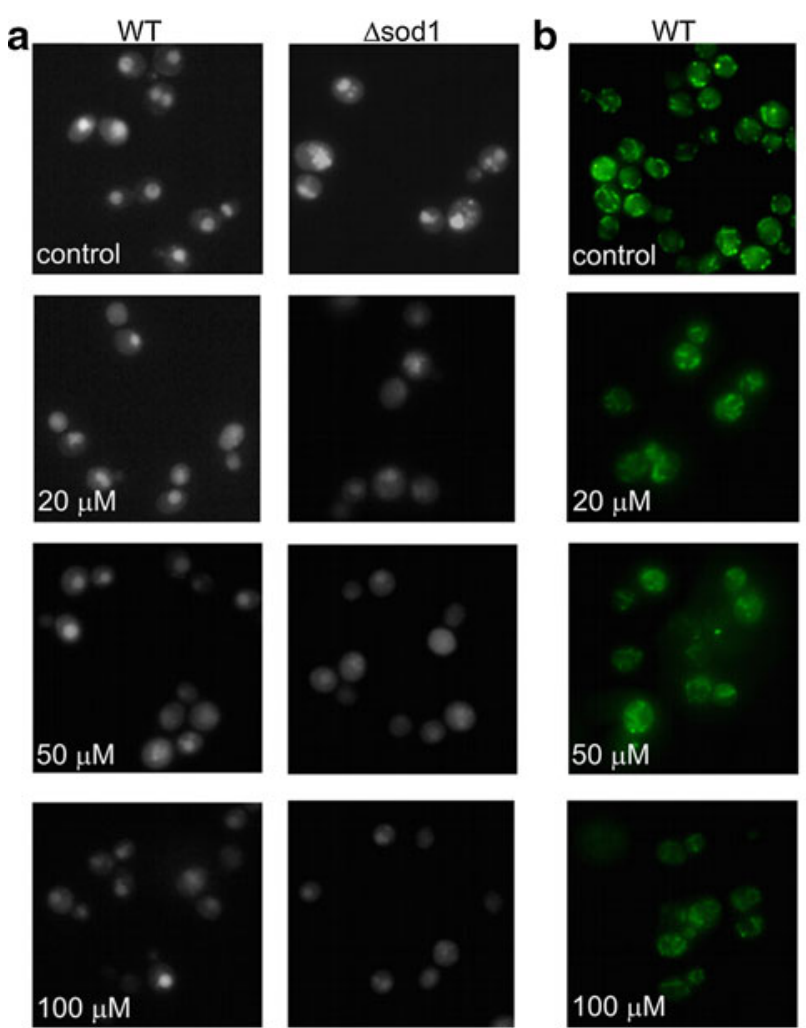
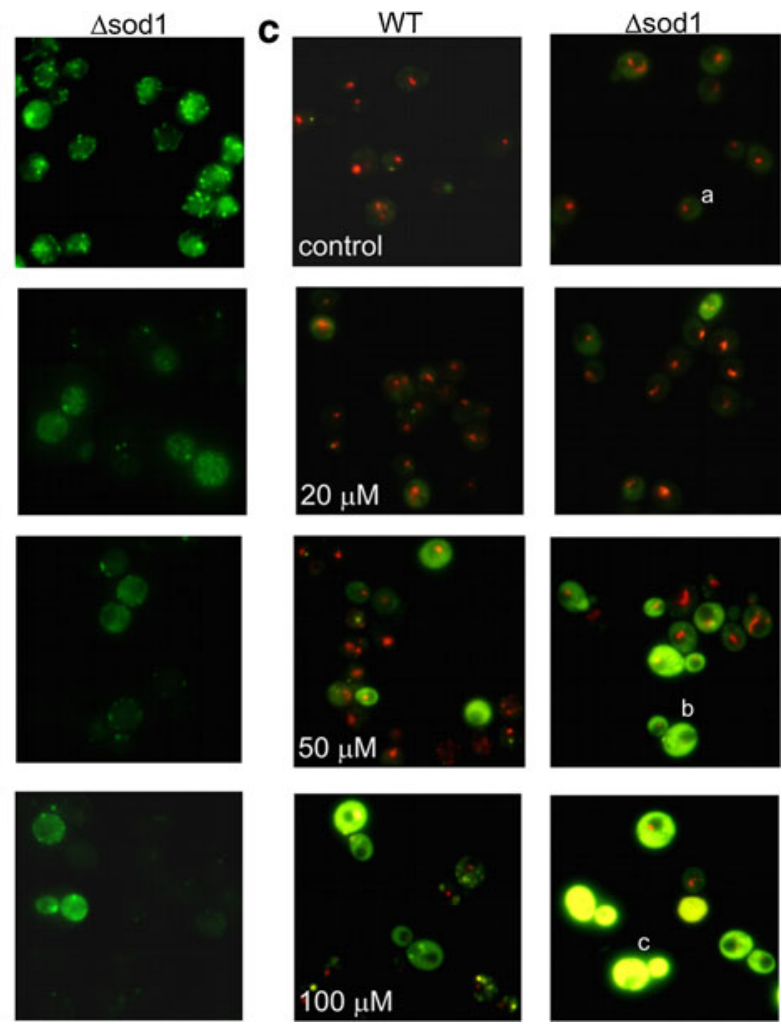

Fig. 3 Effect of DSF $(0-100 \mu \mathrm{M})$ on yeast cells. a Changes in GSH content estimated with monochlorobimane. b Changes of mitochondria morphology, cell staining with MitoTrackerGreen. c

(Cen et al. 2002; Grosicka-Maciag et al. 2010; Chen et al. 2001). In this paper, we show that also yeast $S$. cerevisiae may provide new information on the mechanisms of cellular effects of DSF.

Yeast $S$. cerevisiae is widely accepted as a model eukaryotic organism. It has a number of attributes that make it attractive as an experimental system for studies of cell physiology, genetics, and cellular response to various environmental stresses. Despite its simplicity yeast cells are similar to higher eukaryotes in their biochemistry and physiology. Many studies confirm the usefulness of yeast for testing toxicity of xenobiotics including drugs (Yasokawa et al. 2008; Letavayová et al. 2008; Van der Heggen et al. 2010). Yeast can be grown under hypoxia or even complete anoxia, which makes yeast cells especially useful for studies of oxidative stress-related mechanisms. Their culture is much cheaper in comparison with mammalian cells. Furthermore, viable disruptants of all genes of $S$. cerevisiae are easily available which can allow for

Changes of metabolic activity, cell staining with FUN-1 ( $a$ metabolically active cell; $b$-metabolically inactive cell; $c$ - dead cell)

screening of genes whose products are important for cellular effects of xenobiotics.

Our results demonstrate that yeast cells lacking $\mathrm{Cu}$, Zn-superoxide dismutase (Sod1p), the enzyme removing superoxide anion, are hypersensitive to DSF. DSF at a concentration of $30 \mu \mathrm{M}$ caused an approximate $50 \%$ growth inhibition both in liquid and on solid medium, and completely inhibited growth of $\Delta$ sodl mutant cells at a concentration of $50 \mu \mathrm{M}$ (Fig. 1b, c). We demonstrated that WT strain is also sensitive to DSF but growth inhibition is observed at higher concentrations (e.g., $75 \mu \mathrm{M}$ of DSF; Fig. 1a, c). It is worth noting that almost the same concentrations were used in experiments with $S$. cerevisiae $\Delta p s o 2$ mutant $(0-$ $30 \mu \mathrm{M}$ DSF) (Brendel et al. 2010), C. albicans (0$100 \mu \mathrm{M}$ DSF) (Shukla et al. 2004), and astrocytes (0$100 \mu \mathrm{M}$ DSF) (Chen et al. 2001). Thus, the sensitivity of very different cells to DSF is similar which may well justify the use of yeast cells in studies of the mechanism of action of this compound. 
Fig. 4 Effect of antioxidants and anoxic atmosphere on yeast cell growth inhibition induced by $50 \mu \mathrm{M}$ DSF.

a Yeast cells were cultured in liquid medium with antioxidants (5 mM ASC, CYS, GSH, NAC; 2.5 mM DTT; $0.5 \mathrm{mM}$ Tempo, Tempol and $1 \mathrm{mM}$ Trolox) and growth rate was monitored turbidimetrically after $18 \mathrm{~h}$. Data represent mean \pm SD from three independent experiments, asterisks denote statistical significance with respect to wild-type yeast $* P<0.05, * * P<0.01$, $* * * P<0.001$, estimated by the $t$ test for independent samples. The letters $a$ and $c$ indicate significantly different values from DSF treated sample with the same yeast strain using ANOVA and Dunnet post hoc test at a $P<0.05$, c $P<0.001$, respectively. b Yeast cells were grown on solid medium with the same antioxidants. c Yeast cells were grown on solid medium under anoxic atmosphere. For spotting tests colony growth was recorded after $48 \mathrm{~h}$. Successive spots contained 50,000, $5,000,500$, and 50 cells

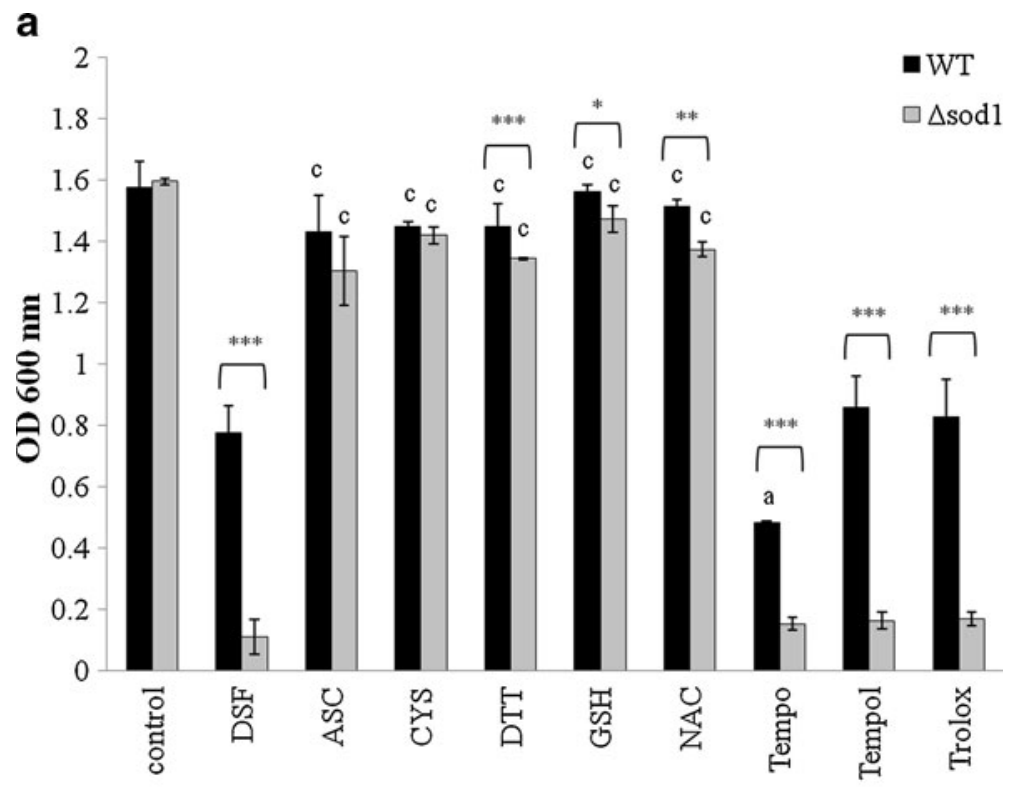

b

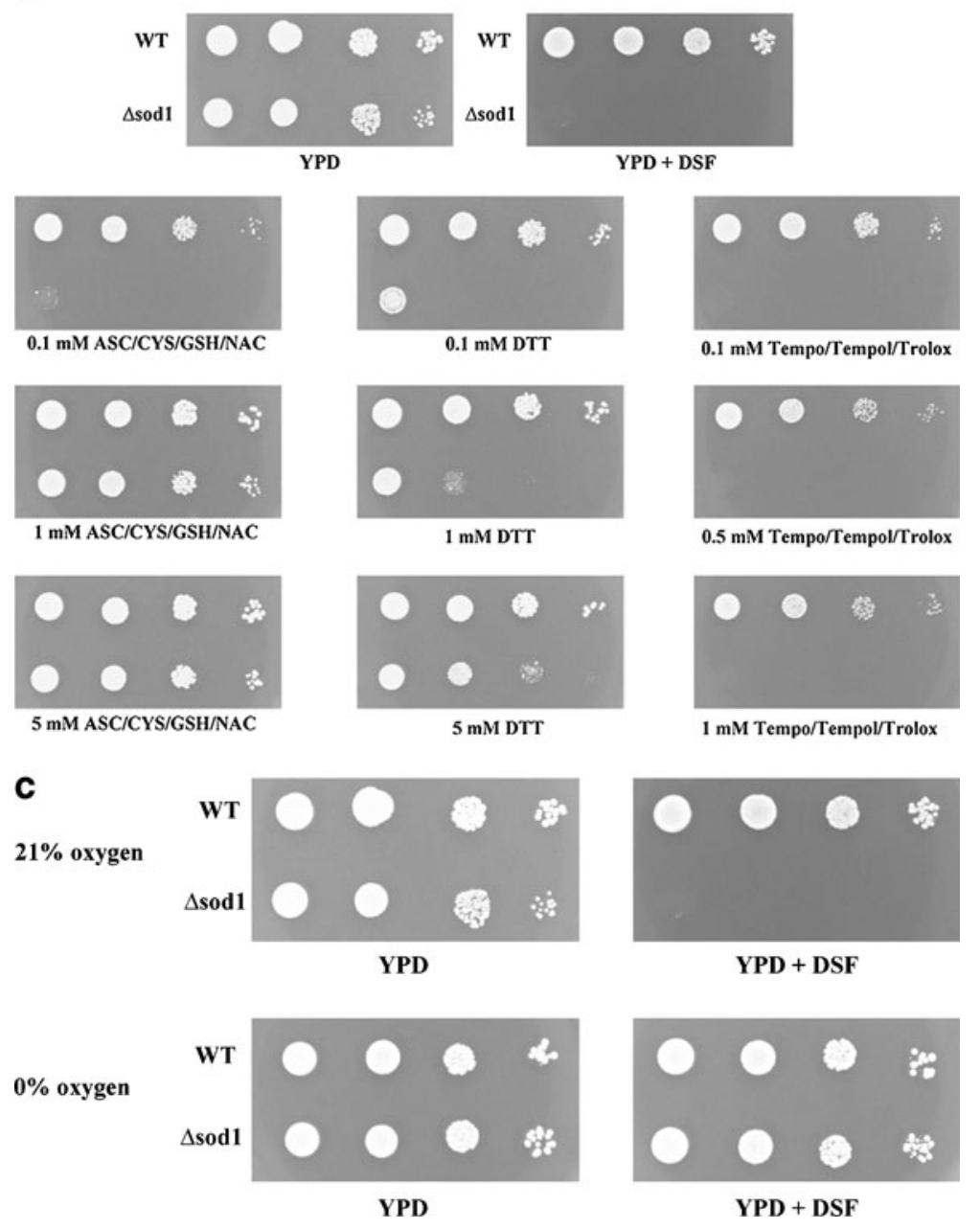


Our results show that DSF causes oxidative stress in yeast cells by significantly increasing superoxide generation (Fig. 2), and depletion of glutathione (Fig. 3a). Longer incubation (3-h) with 50 and $100 \mu \mathrm{M}$ DSF causes also morphological changes, disintegration of mitochondria (Fig. 3b), and decrease of metabolic activity of cells (Fig. 3c). Mitochondria are known to be an important target for many oxidants and dynamic changes in their morphology may be accompanied by loss of mitochondrial membrane potential. Furthermore, these alterations as well as disintegration of mitochondria may be a trigger for apoptosis (Eisenberg et al. 2007).

The potential mechanism of DSF toxicity may be linked to the copper chelating activity of this compound. Though DSF does not inhibit superoxide dismutase in vitro, it decreases the activity of this enzyme in vivo, apparently due to reduction to diethyldithiocarbamate (DDC), a strong SOD inhibitor (Forman et al. 1980). In erythrocytes, DSF was found to oxidize GSH to GSSG and inhibit SOD, and these effects were ascribed to reduction of this compound to DDC as well (Kelner \& Alexander 1986). Reduction of DSF to DDC and inhibition of $\mathrm{Cu}, \mathrm{Zn}$-superoxide dismutase leading to increase in superoxide steady state level and oxidation of glutathione seems also to be a plausible mechanism contributing to the effects of this compound in yeast.

The role of oxidative stress in the toxicity of DSF is confirmed by elimination of hypersensitivity of $\Delta$ sod1 mutant cells to this compound under anoxia (Fig. 4c), and by the protection offered by some hydrophilic antioxidants: ascorbate, reduced glutathione, dithiothreitol, cysteine, and $\mathrm{N}$-acetylcysteine (Fig. 4a, b). Amelioration of the effects of DSF by DTT and NAC has been reported previously for $C$. albicans (Shukla et al. 2004) and Chinese hamster fibroblast cells (Grosicka-Maciag et al. 2010). Protective effects of ascorbate and other hydrophilic antioxidants on DSF-induced oxidative stress have not been well studied. Yeast seems to be a useful eukaryotic model for studies of these effects at the cellular level.

Interestingly, some of antioxidants used like Tempo, Tempol, and Trolox had no protective effect (Fig. 4a, b). The same pattern of antioxidant action was found when studying rescue of $\Delta \operatorname{sod} 1$ mutant cells from other oxidants including tert-butyl hydroperoxide, cumene hydroperoxide, menadione, juglone, hypochlo- rite, chlorite, oxytetracycline, acrolein, acrylamide, and hypertonic stress (Koziol et al. 2005; Lewinska et al. 2004; Kwolek-Mirek et al. 2009; Kwolek-Mirek et al. 2011), which suggests that DSF induces oxidative stress by a mechanism similar to that of other oxidants.

In summary, our data show that yeast $S$. cerevisiae is sensitive to DSF. We demonstrate the important role of $\mathrm{Cu}, \mathrm{Zn}$-superoxide dismutase (Sod1p) in protection against DSF-induced oxidative stress. Hydrophilic antioxidants: ascorbate, cysteine, reduced glutathione, ditiothreitol, and $\mathrm{N}$-acetylcysteine can abolish DSFinduced toxicity in yeast cells. The observation that not only thiol antioxidants but also ascorbate can protects from DSF toxicity may be useful in further studies and be of importance for the anti-alcoholic therapy in humans.

Open Access This article is distributed under the terms of the Creative Commons Attribution Noncommercial License which permits any noncommercial use, distribution, and reproduction in any medium, provided the original author(s) and source are credited.

\section{References}

Bilinski T, Lukaszkiewicz J, Sledziewski A. Demonstration of anaerobic catalase synthesis in the cz1 mutant of Saccharomyces cerevisiae. Biochem Biophys Res Commun. 1978;83(3):1225-33.

Bouma MJ, Snowdon D, Fairlamb AH, Ackers JP. Activity of disulfiram (bis(diethylthiocarbamoyl)disulphide) and ditiocarb (diethyldithiocarbamate) against metronidazolesensitive and -resistant Trichomonas vaginalis and Tritrichomonas foetus. J Antimicrob Chemother. 1998;42 (6):817-20.

Brendel M, Marisco G, Ganda I, Wolter R, Pungartnik C. DNA repair mutant pso2 of Saccharomyces cerevisiae is sensitive to intracellular acetaldehyde accumulated by disulfiram-mediated inhibition of acetaldehyde dehydrogenase. Genet Mol Res. 2010;9(1):48-57.

Burkitt MJ, Bishop HS, Milne L, Tsang SY, Provan GJ, Nobel CSI, et al. Dithiocarbamate toxicity toward thymocytes involves their copper-catalyzed conversion to thiuram disulfides, which oxidize glutathione in a redox cycle without the release of reactive oxygen species. Arch Biochem Biophys. 1998;353(1):73-84.

Cen D, Gonzalez RI, Buckmeier JA, Kahlon RS, Tohidian NB, Meyskens FL. Disulfiram induces apoptosis in human melanoma cells: a redox-related process. Mol Cancer Ther. 2002;1(3):197-204.

Chen SH, Liu SH, Liang YC, Lin JK, Lin-Shiau SY. Oxidative stress and c-Jun-amino-terminal kinase activation involved in apoptosis of primary astrocytes induced by disulfiramCu2+ complex. Eur J Pharmacol. 2001;414(2-3):177-88. 
Eisenberg T, Büttner S, Kroemer G, Madeo F. The mitochondrial pathway in yeast apoptosis. Apoptosis. 2007;12(5):1011-23.

Forman HJ, York JL, Fisher AB. Mechanism for the potentiation of oxygen toxicity by disulfiram. J Pharmacol Exp Ther. 1980;212(3):452-5.

Grosicka-Maciag E, Kurpios-Piec D, Grzela T, Czeczot H, Skrzycki $\mathrm{M}$, Szumilo M, et al. Protective effect of $\mathrm{N}$-acetyl-l-cysteine against disulfiram-induced oxidative stress and apoptosis in V79 cells. Toxicol Appl Pharmacol. 2010;248(3):210-6.

Heikkila RE, Cabbat FS, Cohen G. In vivo inhibition of superoxide dismutase in mice by diethyldithiocarbamate. $\mathrm{J}$ Biol Chem. 1976;251(7):2182-5.

Kelner MJ, Alexander NM. Inhibition of erythrocyte superoxide dismutase by diethyldithiocarbamate also results in oxyhemoglobin-catalyzed glutathione depletion and methemoglobin production. J Biol Chem. 1986;261(4):1636-41.

Khan S, Singhal S, Mathur T, Upadhyay DJ, Rattan A. Antifungal potential of disulfiram. Nippon Ishinkin Gakkai Zasshi. 2007;48(3):109-13.

Koziol S, Zagulski M, Bilinski T, Bartosz G. Antioxidants protect the yeast Saccharomyces cerevisiae against hypertonic stress. Free Radical Res. 2005;39(4):365-71.

Kwolek-Mirek M, Bednarska S, Bartosz G, Biliński T. Acrolein toxicity involves oxidative stress caused by glutathione depletion in the yeast Saccharomyces cerevisiae. Cell Biol Toxicol. 2009;25(4):363-78.

Kwolek-Mirek M, Zadrag-Tecza R, Bednarska S, Bartosz G. Yeast Saccharomyces cerevisiae devoid of $\mathrm{Cu}, \mathrm{Zn}$-superoxide dismutase as a cellular model to study acrylamide toxicity. Toxicol in Vitro. 2011;25(2):573-9.

Letavayová L, Vlasáková D, Spallholz JE, Brozmanová J, Chovanec M. Toxicity and mutagenicity of selenium compounds in Saccharomyces cerevisiae. Mutat Res. 2008;638(1-2):1-10.

Lewinska A, Bilinski T, Bartosz G. Limited effectiveness of antioxidants in the protection of yeast defective in antioxidant proteins. Free Radical Res. 2004;38(11):1159-65.

Loo TW, Bartlett MC, Clarke DM. Disulfiram metabolites permanently inactivate the human multidrug resistance Pglycoprotein. Mol Pharm. 2004;1(6):426-33.

Marikovsky M, Ziv V, Nevo N, Harris-Cerruti C, Mahler O. Cu/ $\mathrm{Zn}$ superoxide dismutase plays important role in immune response. J Immunol. 2003;170(6):2993-3001.

Namazi MR. Potential utility of disulfiram against leishmaniasis. Indian J Med Res. 2008;127(2):193-4.

Nash T, Rice WG. Efficacies of zinc-finger-active drugs against Giardia lamblia. Antimicrob Agents Chemother. 1998;42 (6):1488-92.
Navrátilová J, Jungová P, Vanhara P, Preisler J, Kanicky V, Smarda J. Copper ions regulate cytotoxicity of disulfiram to myeloid leukemia cells. Int J Mol Med. 2009;24 (5):661-70.

Pike MG, Mays DC, Macomber DW, Lipsky JJ. Metabolism of a disulfiram metabolite, $S$-methyl- $N, N$-diethyldithiocarbamate, by flavin monooxygenase in human renal microsomes. Drug Metab Dispos. 2001;29(2):127-32.

Sauna ZE, Peng XH, Nandigama K, Tekle S, Ambudkar SV. The molecular basis of the action of disulfiram as a modulator of the multidrug resistance-linked ATP binding cassette transporters MDR1 (ABCB1) and MRP1 (ABCC1). Mol Pharmacol. 2004;65(3):675-84.

Sauna ZE, Shukla S, Ambudkar SV. Disulfiram, an old drug with new potential therapeutic uses for human cancers and fungal infections. Mol BioSyst. 2005;1(2):127-34.

Shukla S, Sauna ZE, Prasad R, Ambudkar SV. Disulfiram is a potent modulator of multidrug transporter Cdr1p of Candida albicans. Biochem Biophys Res Commun. 2004;322 (2):520-5.

Staleva L, Manga P, Orlow SJ. Pink-eyed dilution protein modulates arsenic sensitivity and intracellular glutathione metabolism. Mol Biol Cell. 2002;13(12):420620.

Tonkin EG, Valentine HL, Milatovic DM, Valentine WM. $N, N$ diethyldithiocarbamate produces copper accumulation, lipid peroxidation, and myelin injury in rat peripheral nerve. Toxicol Sci. 2004;81(1):160-71.

Van der Heggen M, Martins S, Flores G, Soares E. Lead toxicity in Saccharomyces cerevisiae. Appl Microbiol Biotechnol. 2010;88(6):1355-61.

Veverka KA, Johnson KL, Mays DC, Lipsky JJ, Naylor S. Inhibition of aldehyde dehydrogenase by disulfiram and its metabolite methyl diethylthiocarbamoyl-sulfoxide. Biochem Pharmacol. 1997;53(4):511-8.

Viquez OM, Valentine HL, Friedman DB, Olson SJ, Valentine WM. Peripheral nerve protein expression and carbonyl content in N, N-diethlydithiocarbamate myelinopathy. Chem Res Toxicol. 2007;20(3):370-9.

Wang F, Zhai S, Liu X, Li L, Wu S, Dou QP, et al. A novel dithiocarbamate analogue with potentially decreased ALDH inhibition has copper-dependent proteasome-inhibitory and apoptosis-inducing activity in human breast cancer cells. Cancer Lett. 2011;300(1):87-95.

Yasokawa D, Murata S, Kitagawa E, Iwahashi Y, Nakagawa R, Hashido T, et al. Mechanisms of copper toxicity in Saccharomyces cerevisiae determined by microarray analysis. Environ Toxicol. 2008;23(5):599-606. 